\title{
Cholecystokinin and response modifications in hippocampal field CA1
}

\author{
DENNIS DAHL and BENJAMIN B. LECOMPTE III \\ University of Texas at Dallas, Richardson, Texas
}

\begin{abstract}
This study indicates that cholecystokinin (CCK-8S) and high-frequency afferent stimulation (HFS) modify neuronal responses to stimulation of the perforant pathway in hippocampal field CA1. HFS, previously neutral with regard to modifications, induced depression of both field evoked action potentials (EAPs) and field excitatory postsynaptic potentials (EPSPs) in the presence of $500 \mathrm{nM}$ CCK-8S. However, in the presence of $1 \mu \mathrm{M}$ CCK-8S, HFS induced a potentiation of both field evoked responses. With intermediate concentrations of CCK-8S, HFS was indifferent to potentiation or depression: $750 \mathrm{nM}$ CCK-8S was not associated with modifications, whereas only potentiation of EAPs occurred with $900 \mathrm{nM}$ CCK-8S. The mechanism underlying HFS/CCK-8S-induced LTP or LTD may involve reduction of $\gamma$-aminobutyric acid (GABA) release. LTP and LTD may underlie certain forms of memory, and this study implicates hippocampal CCK-8S/GABAergic pathways in their induction.
\end{abstract}

The neuronal substrate of memory in the mammalian brain may involve modifications that persist well beyond their period of activation. Long-term potentiation (LTP) or long-term depression (LTD) are examples of such modifications (Bliss \& Lomo, 1973; Levy \& Steward, 1979). In the hippocampal formation, support for a presumptive relationship between long-lasting neuronal modifications and memory is provided by the finding that aphosphonopentanoic acid (APV), an $N$-methyl-Daspartate (NMDA) receptor antagonist, which blocks induction of long-lasting potentiation or depression (Dahl \& Sarvey, 1990; Harris, Ganong, \& Cotman, 1984), also prevents acquisition in behavioral tasks (Morris, 1989; Morris, Anderson, Lynch, \& Baudry, 1986).

LTP and LTD can be induced by high-frequency stimulation (HFS) of afferent pathways (Bliss \& Lomo, 1973; Levy \& Steward, 1979). Induction may involve an associative interaction within an afferent pathway (McNaughton, Douglas, \& Goddard, 1978), but there is ample evidence implicating interactions between pathways as well. In addition to excitatory neurotransmission, induction of LTP in the hippocampal formation involves modulation of GABAergic inhibitory neurotransmission (Wigstrom \& Gustafsson, 1983); neuromodulators such as norepinephrine (NE; Hopkins \& Johnston, 1984); or the neuropeptides somatostatin (Scharfman, 1993) or cholecystokinin (CCK-8S; Dahl, Bennett, \& LeCompte, 1992; Kawasaki \& Yasui, 1992). In addition to effects on the induction of LTP, CCK-8S also facilitates acquisition

This work was supported by a Whitehall Foundation grant awarded to D.D. The authors are affiliated with the Cognition and Neuroscience Program, School of Human Development, The University of Texas at Dallas. The authors are grateful to Ms. Jingmin Li for expert technical assistance in these experiments and preparation of data and the manuscript. Correspondence should be addressed to D. Dahl, School of Human Development, GR 4.1, The University of Texas at Dallas, Richardson, TX 75080. in behavioral tasks (Fekete et al., 1984; Flood, Smith, \& Morely, 1987; Telegdy, Kadar, \& Fekete, 1985).

Differentiation of HFS-induced long-lasting potentiation or depression correlates with postsynaptic membrane potential (Artola, Broecher, \& Singer, 1990; Xie, Berger, \& Barrionuevo, 1992). If CCK-8S modulates GABA release in hippocampal field CAl, as was suggested by Rich-Bennett, Dahl, and LeCompte (1993) for the dentate gyrus, then CCK-8S may also modulate induction of potentiation or depression. In the present work, hippocampal slices were perfused with several concentrations of CCK-8S in conjunction with HFS to determine whether CCK-8S provides an additional factor in the differential induction of LTP or LTD.

\section{METHOD}

\section{Preparation}

Middorsal hippocampal slices $(400 \mu \mathrm{m})$ were cut from the brains of male rats (Sprague-Dawley, 100-125 g) using a McIlwain Tissue Chopper. Slices were placed on a nylon net in a modified Andersen-type chamber at the interface between circulating artificial cerebrospinal fluid (ACSF) and a warmed, humidified atmosphere consisting of $95 \% \mathrm{O}_{2} / 5 \% \mathrm{CO}_{2}$. Buffered $\operatorname{ACSF}(\mathrm{pH}=$ 7.2) has the following composition (in $\mathrm{mM}$ ): $\mathrm{NaCl} \mathrm{125,} \mathrm{KCl} \mathrm{3}$, $\mathrm{MgSO}_{4} 1.3, \mathrm{CaCl}_{2} 2.4, \mathrm{NaHCO}_{3} 26, \mathrm{NaH}_{2} \mathrm{PO}_{4} 1.25$, and glucose 10. Stabilization of slices occurred over a period of $1 \mathrm{~h}$ with continuous ACSF perfusion at a flow rate of $3 \mathrm{ml} / \mathrm{min}$. The temperature of the chamber was a maintained $31^{\circ} \mathrm{C}$.

\section{Electrophysiological Techniques}

Stimulation electrodes consisted of Teflon-coated platinumiridium wires (ca. $80 \mu \mathrm{m}$ diam) mounted in a drawn glass capillary. A stimulation electrode (S, Figure 1) was placed in the direct perforant pathway (PP) projection from the entorhinal cortex to field CA1 (Doller \& Weight, 1982). The distinctly myelinated PP is adjacent to the hippocampal fissure and comprises, in part, the stratum moleculares-lacunosum. CCK-GABA colocalization (Bartfai, 1985; Hendry et al., 1984) and CCK receptors have been reported in this area (Zarbin, Innis, Wamsley, Snyder, \& Kuhar, 1983). 


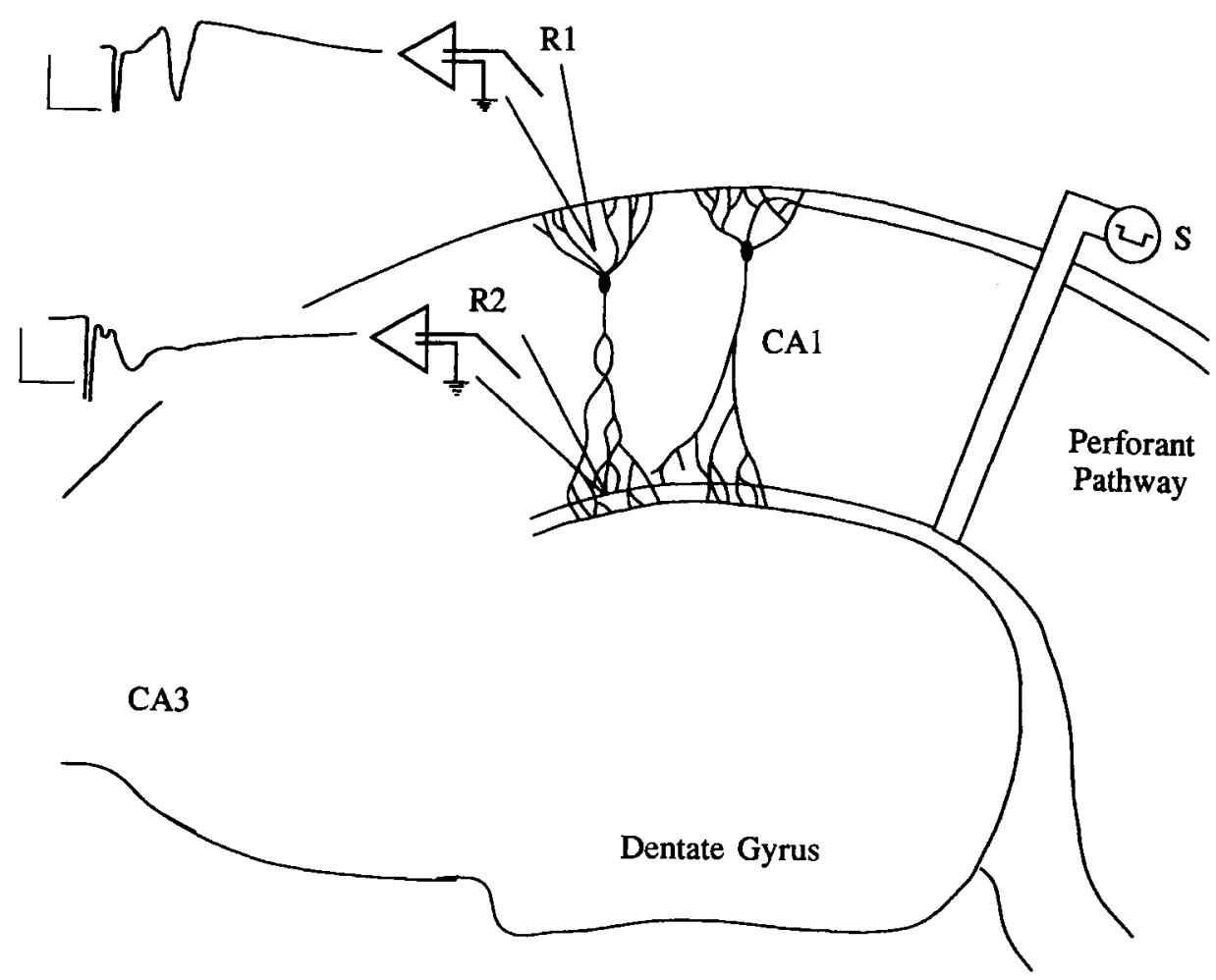

Figure 1. Schematic of a hippocampal slice illustrating a field CA1 pyramidal cell body and dendrites. A recording electrode (R1) placed in stratum pyramidales recorded EAPs (illustrated), and a second recording electrode (R2) placed in stratum moleculares-lacunosum recorded EPSPs (illustrated). A stimulation electrode (S) placed in the perforant pathway delivered single-pulse or HFS. The vertical calibration for EAPs is $2.5 \mathrm{mV}$, and horizontal calibration is 5.0 msec. For EPSPs, the vertical calibration is $2.0 \mathrm{mV}$, and the horizontal calibration is $\mathbf{5 . 0}$ msec.

The PP was selected for activation because it is described as a "weak" projection (Colbert \& Levy, 1992), and the present experiments required an initial HFS that was subthreshold for induction of neuronal modifications. LTP has been induced in the PP (Doller \& Weight, 1982) and LTP and LTD have been reported for other afferents to CA1 pyramidal cells (Stanton \& Sejnowski, 1989). HFS consisted of four trains of 10 pulses at $100 \mathrm{~Hz}$, with a $1-\mathrm{sec}$ intertrain interval. Single-pulse stimulation was delivered at 10 sec intervals. Recording electrodes consisted of drawn glass micropipettes filled with $2 \mathrm{~N} \mathrm{NaCl}$ (5-10 $\mathrm{M} \Omega$ ). Recording electrodes were placed in stratae pyramidales (R1) and moleculares-lacunosum (R2) to obtain simultaneous recordings of evoked action potentials (EAPs) and excitatory postsynaptic potentials (EPSPs; Figure 1). Pulse duration was varied with a fixed current to obtain the input-output characteristics of the preparation. For control responses, a pulse duration was selected that was suprathreshold for EAPs, and for HFS, pulse duration was selected that was $s u b$ threshold for an EAP. Slope and amplitude measurements were obtained using standard procedures with Neuropro (RC Electronics, Goleta, CA), a PC-based system. Data were normalized to mean control values. Mean differences were evaluated against control values after potentiation or depression using the paired $t$ test.

\section{Design and Procedure}

Single-pulse-evoked responses were recorded for a 30-min control period with ACSF perfusion. HFS was applied and responses recorded for a 30 -min post-HFS period (also with ACSF perfusion). If neither potentiation nor depression of responses was in- duced, then a 30-min perfusion with one of several concentrations of CCK-8S was initiated. The sulfated octapeptide of $\mathrm{CCK}^{26-33}$ used in these experiments was purchased from BaChem Bioscience, Inc. (Philadelphia, PA). CCK-8S concentrations in the range of $100 \mathrm{nM}-2.0 \mu \mathrm{M}$ were used in this study.

A second HFS (pulses of the same duration parameter) was applied after $30 \mathrm{~min}$ of CCK-8S perfusion, and wash with CCK8S-free ACSF was immediately initiated. Responses were recorded for a $30-\mathrm{min}$ post-CCK-8S/post-HFS period. A control condition was provided by the application of a second series of subthreshold trains without CCK-8S perfusion.

\section{RESULTS}

Figure 2 illustrates the results obtained with $500-\mathrm{nM}$ CCK-8S perfusion in conjunction with HFS. The $500 \mathrm{nM}$ CCK-8S was without significant effect on EAPs (Figure 2A; $p>.05$ ), but EPSPs were reduced (Figure $2 \mathrm{~B} ;-14.4 \% \pm 6.7 \%, N=6, p<.05$ ). With concurrent HFS, CCK-8S was associated with a persistent $d e$ pression of both EAPs (Figure $2 \mathrm{~A} ;-45.1 \% \pm 14 \%$, $N=6, p<.05$ ) and EPSPs (Figure $2 \mathrm{~B} ;-28.9 \% \pm$ $7.6 \%, N=6, p<.05$ ). Depression persisted for at least 30 min in ACSF wash. The reduction in EPSP slope associated with HFS was larger $(-28.9 \%$ vs. $-14.4 \%, N=6$, $p \cdot 05$ ) than the depression associated with CCK-8S 
$\mathbf{A}$

500 nM CCK-8S
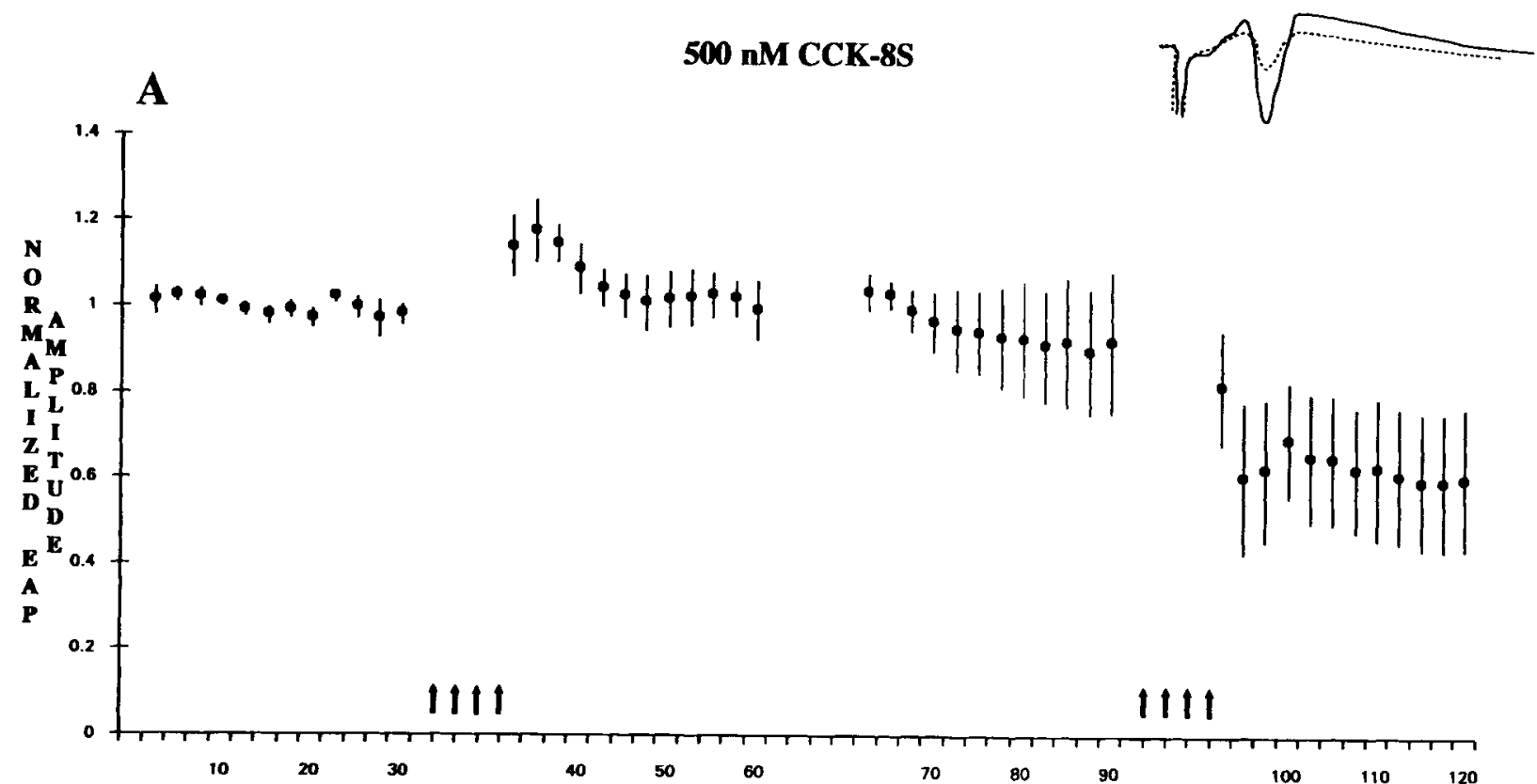

1111

30

60

70

$80 \quad 90$

TIME (MIN)

CCK-8S

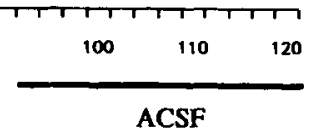

500 nM CCK-8S

B
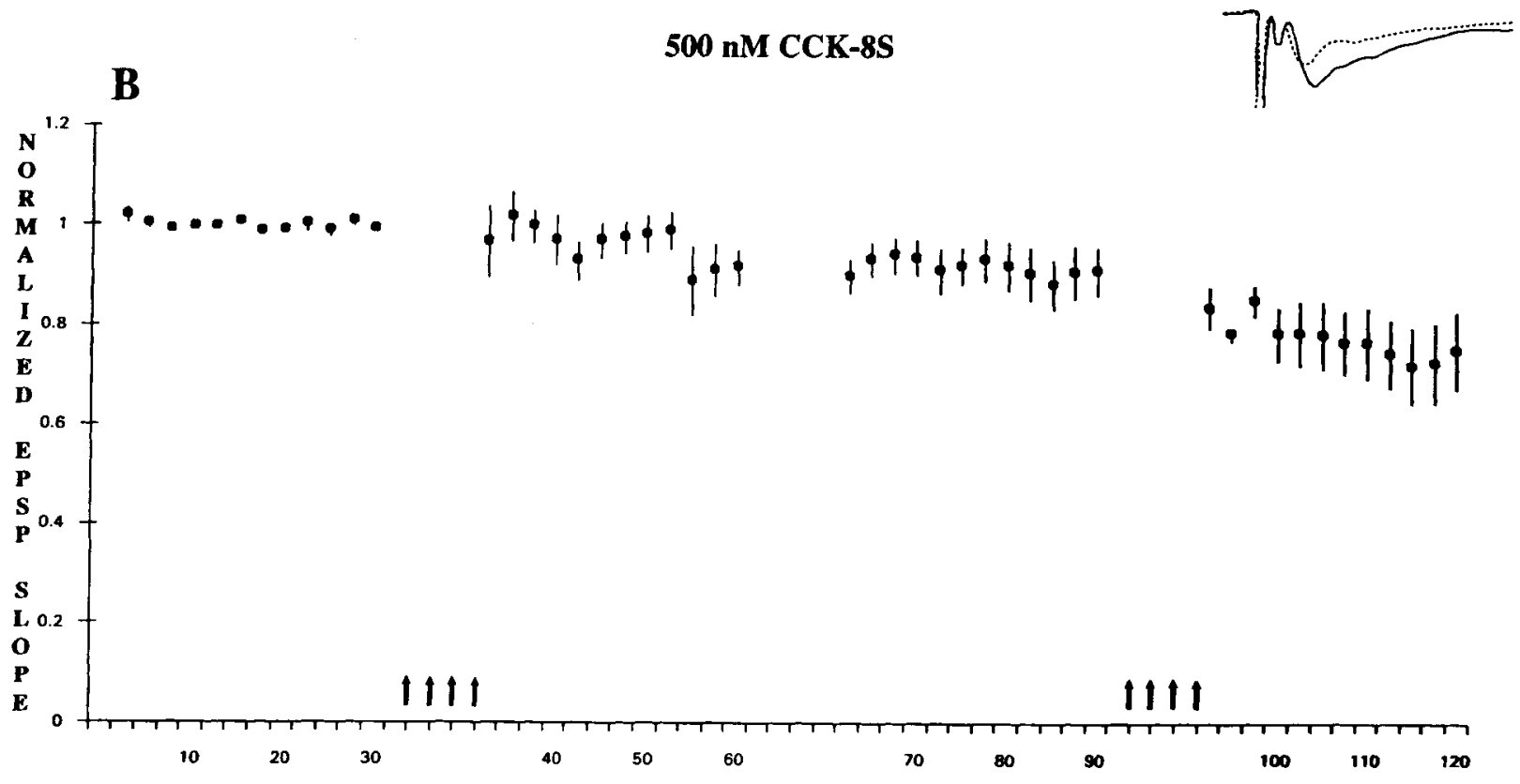

\section{1}

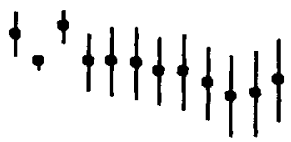

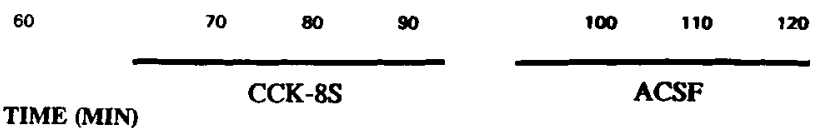

Figure 2. Effect of 500-nM CCK-8S perfusion with and without HFS on stratum pyramidales responses. HFS of the perforant pathway is indicated by four arrows, indicating that four trains (of 10 pulses each) were used (ACSF control and CCK-8S perfusion). EAP (A) and EPSP (B) measurements were normalized to mean control values. Vertical bars indicate standard error of the mean. EAP and EPSP HFS-induced depression differed from control values ( $p<.05, N=6$ ). Inserts illustrate control EAP and EPSP responses (solid lines) and post-CCK-8S/HFS responses (broken lines). Mean baseline EAPs were $2.1 \pm 0.10 \mathrm{mV}$, and mean EPSP slopes were $2.7 \pm 0.09 \mathrm{mV} / \mathrm{msec}$. 


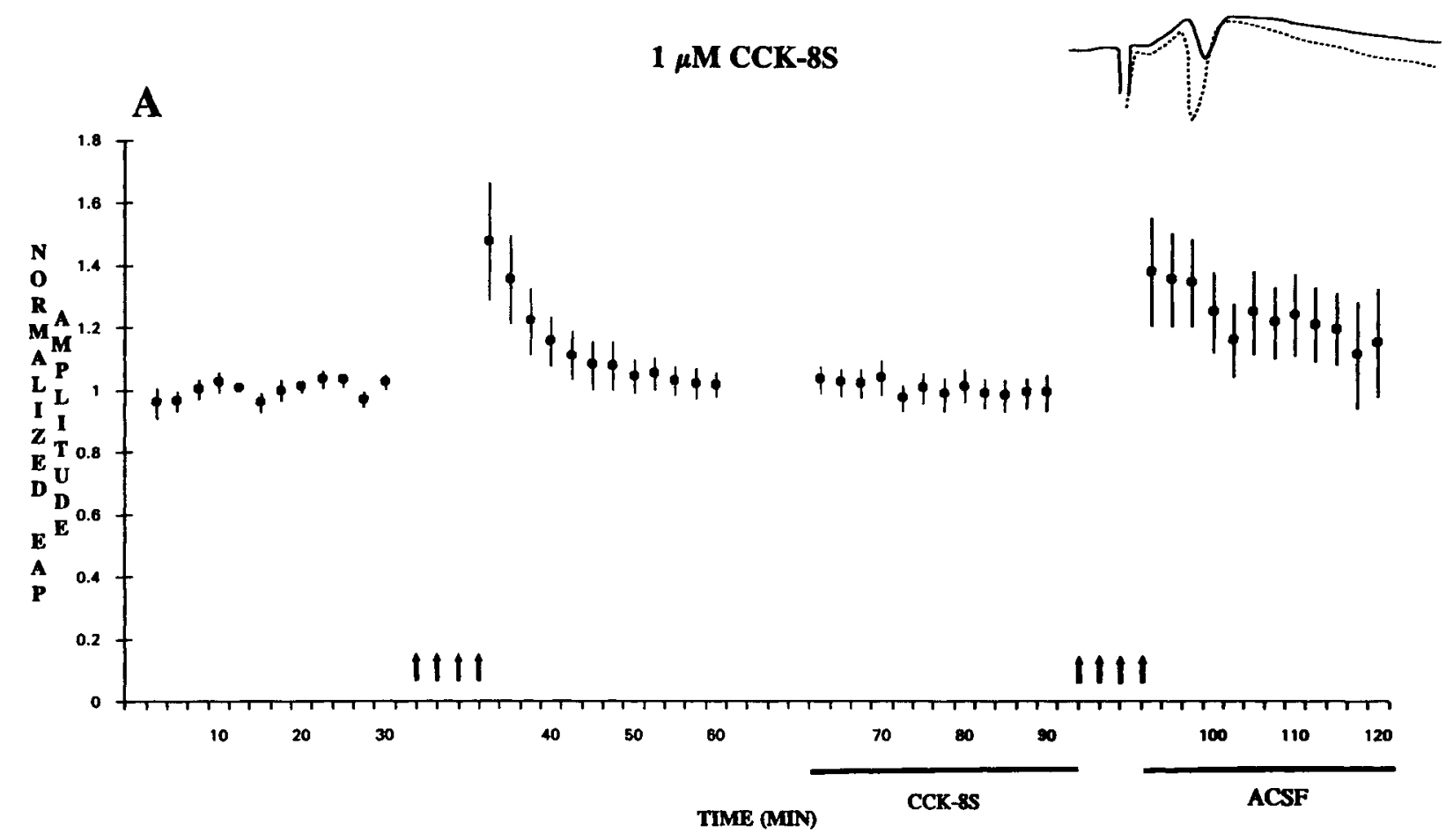

\section{$1 \mu M$ CCK-8S}

B

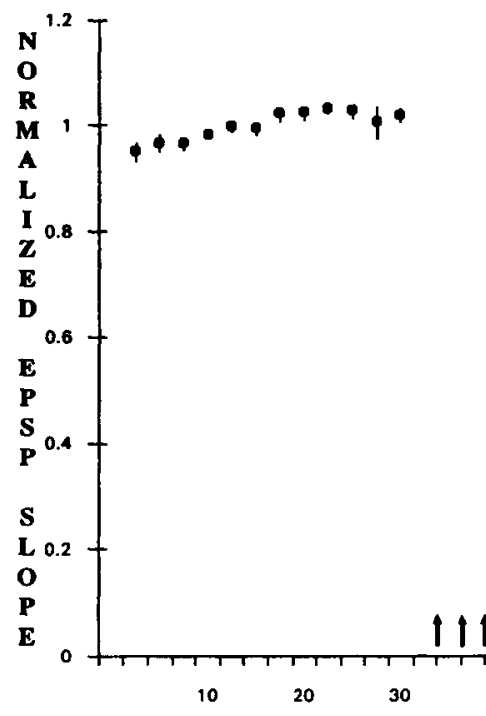

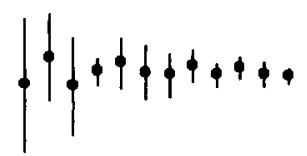

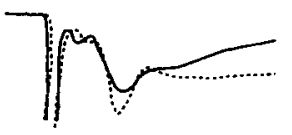

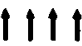

1111

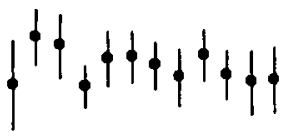


perfusion. Figure 2A shows a slight short-term potentiation of EAPs associated with the initial HFS, which does not appear with concurrent CCK-8S perfusion.

Figure 3 illustrates the results obtained with $1-\mu \mathrm{M}$ CCK-8S perfusion using a protocol identical to that described previously. Like 500-nM CCK-8S perfusion, $1 \mu \mathrm{M}$ CCK-8S was without effect on EAPs (Figure 3A; $N=6, p>.05$ ), but EPSPs were reduced (Figure 3B; $-16 \% \pm 9 \%, N=6, p<.05$ ). With $1-\mu \mathrm{M}$ CCK perfusion, HFS was associated with a persistent significant potentiation of both EAPs (Figure 3A; 27\% $\pm 13 \%$, $N=6, p<.05$ ) and EPSPs (Figure 3B; $9.4 \% \pm 7.0 \%$, $N=6, p<.05$ ). Potentiation persisted for at least $30 \mathrm{~min}$ in ACSF wash. Figure $3 \mathrm{~A}$ also shows a short-term potentiation associated with the initial HFS, which does not appear with concurrent CCK-8S perfusion.

Intermediate concentrations of CCK-8S (not illustrated) were neutral with regard to HFS-associated LTP or LTD. With $750 \mathrm{nM} \mathrm{CCK-8S,} \mathrm{neither} \mathrm{EAPs} \mathrm{nor} \mathrm{EPSPs}$ was potentiated or depressed following HFS. With $900 \mathrm{nM} \mathrm{CCK}-8 \mathrm{~S}$, only potentiation of the EAP was observed $(17.4 \% \pm 5.5 \%, N=6, p<.05)$, whereas EPSPs were unaffected. A CCK-8S concentration $>1.5 \mu \mathrm{M}$ was associated with a total depression of EAPs and EPSPs that reversed to baseline levels upon perfusion with drug-free ACSF.

\section{DISCUSSION}

These results demonstrate a dose dependence of HFS-induced response modifications with CCK-8S in field CA1 of the hippocampal formation. A relatively low concentration of CCK-8S (500 nM), with concurrent HFS, was associated with a persistent depression of both EAPs and EPSPs, whereas a relatively higher concentration of CCK-8S $(1 \mu \mathrm{M})$, with concurrent HFS, was associated with a persistent potentiation of both EAPs and EPSPs. Intermediate concentrations of CCK$8 \mathrm{~S}(750$ or $900 \mathrm{nM})$ were apparently neutral with regard to depression or potentiation, as $750 \mathrm{nM} \mathrm{CCK-8S}$ was not associated with response modification, and $900 \mathrm{nM}$ CCK-8S was associated only with potentiation of EAPs.

The mechanism underlying the effect of CCK-8S and the differential induction of potentiation or depression can only be speculated at this time. In several brain areas, a neuropeptide and classical neurotransmitter are located in the same neuron (Bartfai, 1985; Hendry et al., 1984; Hoekfelt et al., 1987). For example, CCK-8SGABA colocalization is found in the hippocampal formation (Bartfai, 1985; Somogyi et al., 1984), but little is known of their functional relationship. In the case of CCK-8S and dopamine colocalization (Hoekfelt et al., 1980), however, CCK-8S may modulate dopamine release (Voigt, Wang, \& Westfall, 1986). CCK-8S modulates GABA release in the rat solitary complex (Branchereau, Champagnat, Roques, \& Denavit-Saubie, 1992 ) and may similarly modulate GABA in the hippocampal formation.
CCK-8S is a potent neuronal excitant in the hippocampal formation (Boehme, Stutzmann, \& Blanchard, 1988; Dahl, 1987a, 1987b, 1988; Dodd \& Kelly, 1981; Jaffee, Aitken, \& Nadler, 1987). In the dentate gyrus, EAP amplitude varies inversely with EPSP amplitude with CCK-8S application (Dahl, 1987a): EAPs increase in amplitude, while EPSPs decrease in amplitude. This finding is consistent with a depolarization from resting potential (Dahl, Bailey, \& Winson, 1983; Takeuchi \& Takeuchi, 1960), the basis of which may be a CCK-8Sinduced reduction of GABA release (Bartfai, 1985; Branchereau et al., 1992), a postsynaptic action of CCK8S (Buckett \& Saint, 1989), or both. The present results indicate that, whatever the locus of CCK-8S modulation, both synaptic activation (EPSP) and neuronal output (EAP) undergo HFS-induced modifications when used concurrently with CCK-8S concentrations. The present results contrast the finding of baclofen/isoproterenolinduced potentiation in the dentate gyrus (Burgard \& Sarvey, 1991), in which only the EAP was potentiated while the EPSP was unchanged.

The differential induction of depression or potentiation of neuronal responses may involve the instantaneous membrane potential. In the visual cortex, steady-state membrane potential that is close to, but more positive than, resting potential is associated with HFS-induced LTD, whereas stronger steady-state depolarization is associated with HFS-induced LTP (Artola et al., 1990). In hippocampal field $\mathrm{CAl}$ and the dentate gyrus, steadystate hyperpolarization is associated with HFS-induced LTD, whereas LTP is associated with steady-state depolarizations (Stanton, Chattarji, \& Sejnowski, 1991; Xie et al., 1992).

In the dentate gyrus, baclofen (a GABA $\mathrm{G}_{\mathrm{B}}$ agonist) disinhibits hippocampal neurons via reduction of GABA release (Harrison, 1990; Misgeld, Mueller, \& Brunner, 1978). CCK-8S enhanced paired-pulse facilitation in the dentate gyrus in a similar manner (Rich-Bennett, Dahl, \& LeCompte, 1992), suggesting a reduction of non$\mathrm{GABA}_{\mathrm{A}}$-mediated inhibition. In addition, both CCK-8S (Boehme et al., 1988; Buckett \& Saint, 1989; Dodd \& Kelly, 1981; Jaffee et al., 1987) and baclofen (Burgard \& Sarvey, 1991; Misgeld et al., 1978) depolarize hippocampal neurons, further suggesting a CCK-8S-induced reduction of GABA release. In the present study, perfusion with CCK-8S concentrations $>1.5 \mu \mathrm{M}$ was associated with a reversible supression of EPSP and EAP amplitudes. This was attributable to depolarization block (Bunney \& Grace, 1978). Similarly, $1 \mu \mathrm{M} \mathrm{CCK}-8 \mathrm{~S}$ was associated with a reduction of EPSP amplitude, as would likely occur with postsynaptic depolarization (Dahl et al., 1983; Takeuchi \& Takeuchi, 1960). This result is also consistent with known depolarizing effects of CCK$8 \mathrm{~S}$ in field CA1 and the suggestion that CCK-8S induces a reduction of GABA-mediated inhibition. If CCK-8S and GABA are so related, then the results of the present study, demonstrating a dose dependence of potentiation or depression with CCK-8S, are consistent with studies 
that link HFS-induced LTP or LTD to membrane potential by injection of hyperpolarizing or depolarizing currents from an intracellular microelectrode (Artola et al., 1990; Xie et al., 1992).

The present results suggest a neuromodulatory function for CCK-8S in hippocampal field CA1, and implicate CCK-8S-containing intrinsic pathways (Handelmann, Meyer, Bienfeld, \& Oertel, 1981) in the differential induction of LTP or LTD. The substrates and conditions underlying induction of LTP or LTD are of interest because of their relevance to presumptive biological substrates of memory (Teyler \& DiScenna, 1984).

\section{REFERENCES}

Artola, A., Broecher, S., \& Singer, W. (1990). Different voltagedependent thresholds for inducing long-term depression and longterm potentiation in slices of rat visual cortex. Nature, 347, 69-72.

Bartfai, T. (1985). Pre-synaptic aspects of the coexistence of classical neurotransmitters and peptides. Trends in Pharmacological Science, 6, 331-334.

BLiss, T. V. P., \& Lomo, T. (1973). Long-lasting potentiation of synaptic transmission in the dentate area of the anesthetized rabbit following stimulation of the perforant pathway. Journal of Physiology, 334, 475-491.

Boehme, G. A., Stutzmann, J.-M., \& Blanchard, J.-C. (1988). Excitatory effects of cholecystokinin in rat hippocampus: Pharmacological response compatible with "central" or B-type CCK receptors. Brain Research, 451, 309-318.

Branchereau, P., Champagnat, J., Roques, B. P., \& DenavitSAUBIE, M. (1992). CCK modulates inhibitory synaptic transmission in the solitary complex through $\mathrm{CCK}_{\mathrm{B}}$ sites. NeuroReports, $\mathbf{3}$, 909-912.

BucketT, K. J., \& SAINT, D. A. (1989). Cholecystokinin modulates voltage dependent $\mathrm{K}^{+}$currents in cultured rat hippocampal neurones. Neuroscience Letters, 107, 162-166.

BunNey, B. S., \& Grace, A. A. (1978). Acute and chronic haloperidol treatment: Comparison of effects on nigral dopaminergic cell activity. Life Sciences, 23, 1715-1728.

Burgard, E. C., \& SARVeY, J. M. (1991). Long-lasting potentiation and epileptiform activity produced by $\mathrm{GABA}_{\mathrm{B}}$ receptor activation in the dentate gyrus of rat hippocampal slice. Journal of Neuroscience, 11, 1198-1209.

Colbert, C., \& Levy, W. B. (1992). Electrophysiological and pharmacological characterization of perforant path synapses in CA1: Mediation by glutamate receptors. Journal of Neurophysiology, 68, $1-8$.

DAHL, D. (1987a). Single-pulse stimulation of the medial perforant pathway with concurrent administration of CCK-8S appears to potentiate the rat dentate gyrus EAP. Society for Neuroscience $A b$ stracts, 13, 463.

DAHL, D. (1987b). Systemically administered cholecystokinin affects an evoked potential in the hippocampal dentate gyrus. Neuropeptides, 10, 165-173.

DAHL, D. (1988). Central administration of cholecystokinin potentiates evoked potential amplitude in the hippocampal dentate gyrus. Neuropeptides, 11, 147-151.

DAHL, D., BAILEY, W. H., \& Winson, J. (1983). Effect of norepinephrine depletion of the hippocampus on neuronal transmission through the dentate gyrus. Journal of Neurophysiology, 49, 123-133.

DAHL, D., BENNETT, E. R., \& LECoMPTE, B. B., III (1992). Interaction of cholecystokinin and afferent tetanization in the induction of synaptic modifications in field CA1 of the rat hippocampal slice. Society for Neuroscience Abstracts, 18, 125.

DAHL, D., \& SARVEY, J. M. (1990). $\beta$-adrenergic agonist-induced longlasting synaptic modifications in hippocampal dentate gyrus require activation of NMDA receptors, but not electrical activation of afferents. Brain Research, 526, 347-350.
DODD, J., \& KELLY, J. S. (1981). The effects of cholecystokinin and related peptides on neurons of the mammalian hippocampus. Brain Research, 205, 337-350.

DOller, H. J., \& WeIGHT, F. F. (1982). Perforant path activation of hippocampal CA1 stratum pyramidales neurons: Electrophysiological evidence for a direct pathway. Brain Research, 237, 1-13.

Fekete, M., Lengyel, A., Hegedus, B., Penke, B., Zarandy, M., ToTH, G., \& TELEGDY, G. (1984). Further analysis of cholecystokinin octapeptides on avoidance behavior in rats. European Journal of Pharmacology, 98, 79-91.

FLOOD, J., SMITH, G., \& MORELY, J. (1987). Modulation of memory processing by cholecystokinin: Dependence on the vagus nerve. Science, 236, 832-834.

Handelmann, G. E., Meyer, D. K., Bienfeld, M. C., \& Oertel, W. H. (1981). CCK-containing terminals in the hippocampus are derived from intrinsic neurons: An immunohistochemical and radioimmunological study. Brain Research, 224, 180-184.

Harris, E. W., Ganong, A. H., \& Cotman, C. W. (1984). Long-term potentiation in the hippocampal formation involves activation of $N$ methyl-D-aspartate receptors. Brain Research, 323, 132-137.

HaRRISON, N. L. (1990). On the presynaptic action of baclofen at inhibitory synapses between cultured rat neurones. Journal of Physiology, 422, 433-446.

Hendry, S. H. C., Jones, E. G., DeFelipe, J., Schmechel, D., BranDON, C., \& EMSON, P. C. (1984). Neuropeptide-containing neurons of the cerebral cortex are also GABAergic. Proceedings of the $\mathrm{Na}$ tional Academy of Science, 81, 6526-6530.

Hoekfelt, T., Millhorn, K., Seroogy, K., Tsuruo, Y., CeccaTelli, S., Lindh, B., Meister, B., Melander, T., Schalling, M., BarTfai, T., \& Terenius, L. (1987). Coexistence of peptides with classical neurotransmitters. Experientia, 43, 678-680.

Hoekfelt, T., Rehfeld, J. F., Skirboll, L., Ivemark, B., GoldSTEIN, M., \& MARKEY, K. (1980). Evidence for coexistence of dopamine and CCK in meso-limbic neurons. Nature, 284, 476-478.

HoPKINS, W. F., \& JoHNSTON, D. (1984). Frequency-dependent noradrenergic modulation of long-term potentiation in the hippocampus. Science, 226, 350-352.

JAFFEE, D. B., AITKEN, P. G., \& NADLER, J. V. (1987). The effects of cholecystokinin and cholecystokinin antagonists on synaptic function in the CA1 region of the rat hippocampal slice. Brain Research, 415, 197-203.

KaWASAKI, K., \& Yasui, M. (1992). Neuroprotective and LTPenhancing effects of cholecystokinin in hippocampal slices. Society for Neuroscience Abstracts, 18, 193.

LEVY, W. B., \& STEWARD, O. (1979). Synapses as associative memory elements in the hippocampal formation. Brain Research, 175, 233 245.

McNaughton, B. L., Douglas, R. M., \& Goddard, G. V. (1978). Synaptic enhancement in the fascia dentata: Cooperativity among coactive afferents. Brain Research, 157, 277-293.

Misgeld, U., MUELleR, W., \& BRUNNER, H. (1978). Effects of (-) baclofen on inhibitory neurons in guinea pig hippocampal slice Pfluegers Archives, 414, 139-144.

MoRRIS, R. G. M. (1989). Synaptic plasticity and learning: Selective impairment of learning in rats and blockade of long-term potentiation in vivo by the $N$-methyl-D-aspartate receptor antagonist, AP5. Journal of Neuroscience, 9, 3040-3057.

Morris, R. G. M., ANDerson, G. S., LyNCH, G. S., \& BAUdRY, M. (1986). Selective impairment of learning and blockade of long-term potentiation by an $N$-methyl-D-aspartate receptor antagonist, AP5. Nature, 319, 774-776.

Rich-BenNeTt, E., DAHL, D., \& LeCompte, B. B., III (1993). Modulation of paired-pulse activation in hippocampal dentate gyrus by cholecystokinin and bicuculline. Neuropeptides, 24, 263-270.

SCHarfman, H. E. (1993). Presynaptic and postsynaptic actions of somatostatin in area $\mathrm{CAl}$ and the dentate gyrus of rat and rabbit hippocampal slices. In T. V. Dunwiddie \& D. M. Lovinger (Eds.), Presynaptic receptors (pp. 246-255). New York: Raven Press.

Somogyi, P., Hodgson, A. J., Smith, A. D., Nunzi-Gracia, M. Gorjo, A., \& WU, J.-Y. (1984). Different populations of GABAergic neurons in the visual cortex and hippocampus of cat contain so- 
matostatin- or cholecystokinin-immunoreactive material. Journal of Neuroscience, 4, 2590-2603.

Stanton, P. K., Chattarji, S., \& Sejnowski, T. J. (1991). 2-amino3-phosphopropionic acid, an inhibitor of glutamate-stimulated phosphoinositide turnover, blocks induction of homosynaptic longterm depression, but not potentiation, in rat hippocampus. Neuroscience Letters, 127, 161-166.

Stanton, P. K., \& SEJNOwSKI, T. (1989). Associative long-term depression in the hippocampus induced by Hebbian covariance. $\mathrm{Na}$ ture, 339, 215-218.

TAKEUCHI, A., \& TAKEUCHI, N. (1960). On the permeability of endplate membrane during the action of transmitter. Journal of Physiology, 154, 52-67.

Telegdy, G., Kadar, T., \& Fekete, M. (1985). Cholecystokinin, learning and memory. In B. Will, P. Schmidt, \& J. Dalrymple-Alford (Eds.), Brain plasticity, learning and memory (pp. 316-333). New York: Plenum

TEYler, T. J., \& DiScenNa, P. (1984). Long-term potentiation and a candidate mnemonic device. Brain Research Reviews, 7, 15-28.
Voigt, M., WANG, R. Y., \& WestFall, T. C. (1986). Cholecystokinin octapeptides alter the release of endogenous dopamine from rat nucleus accumbens in vitro. Journal of Pharmacology \& Experimental Therapeutics, 237, 147-153.

Wigstrom, H., \& Gustafsson, B. (1983). Facilitated induction of hippocampal long-term potentiation during blockade of inhibition. Nature, 301, 603-604.

Xie, X., Berger, T. W., \& Barrionuevo, G. (1992). Isolated NMDA receptor-mediated synaptic responses express both LTP and LTD. Journal of Neurophysiology, 67, 1009-1013.

ZARBIN, M. A., INNIS, R. B., WAMSLEY, S., SNYDER, S. H., \& Kuhar, M. J. (1983). Autoradiographic localization of cholecystokinin receptors in rodent brain. Journal of Neuroscience, 3, 877-906.

(Manuscript received April 30, 1993;

revision accepted for publication December 9, 1993.) 